Stereoselective Formal Synthesis of (+)- and (-)-Cyclophellitol, $(-)$-Conduritol-B and Synthesis of (-)-Conduramine-B Derivative Using a Sulfinyl Moiety for $\mathrm{C}-\mathrm{O}$ Bond Formation and $\alpha$-Chloro Sulfide for C-C Bond Formation

Sadagopan Raghavan*, Ravi Kumar Chiluveru, S. Ganapathy Subramanian

Natural Products Chemistry Division, Indian Institute of Chemical Technology, Hyderabad500007, India.

sraghavan@iict.res.in

Table of Contents

${ }^{1} \mathrm{H}$ NMR and ${ }^{13} \mathrm{C}$ NMR spectra
Page No.

S2-S24 
Compound 8
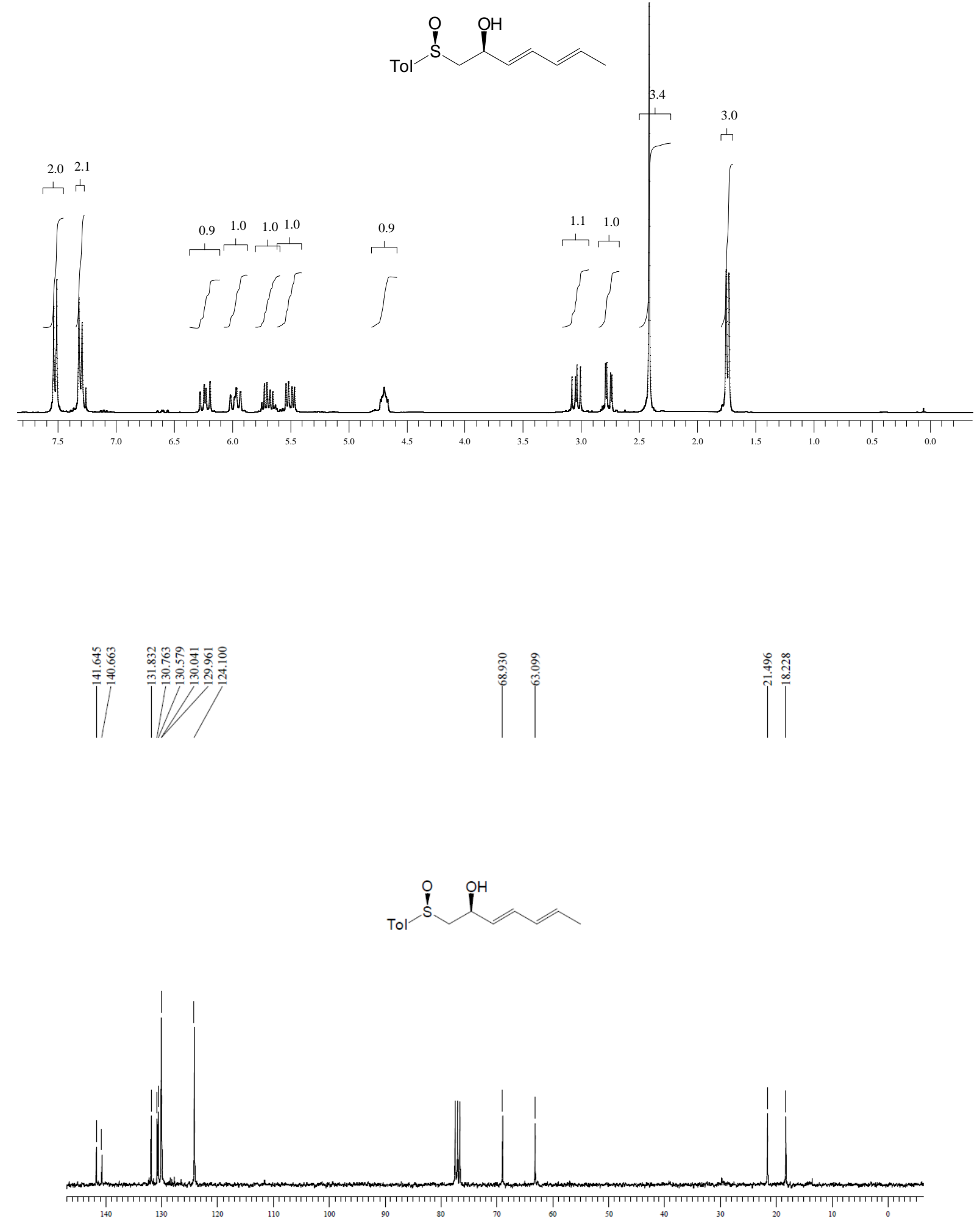
Compound 11<smiles>C/C=C/C(O)C(Br)C(O)CS(=O)OC</smiles>
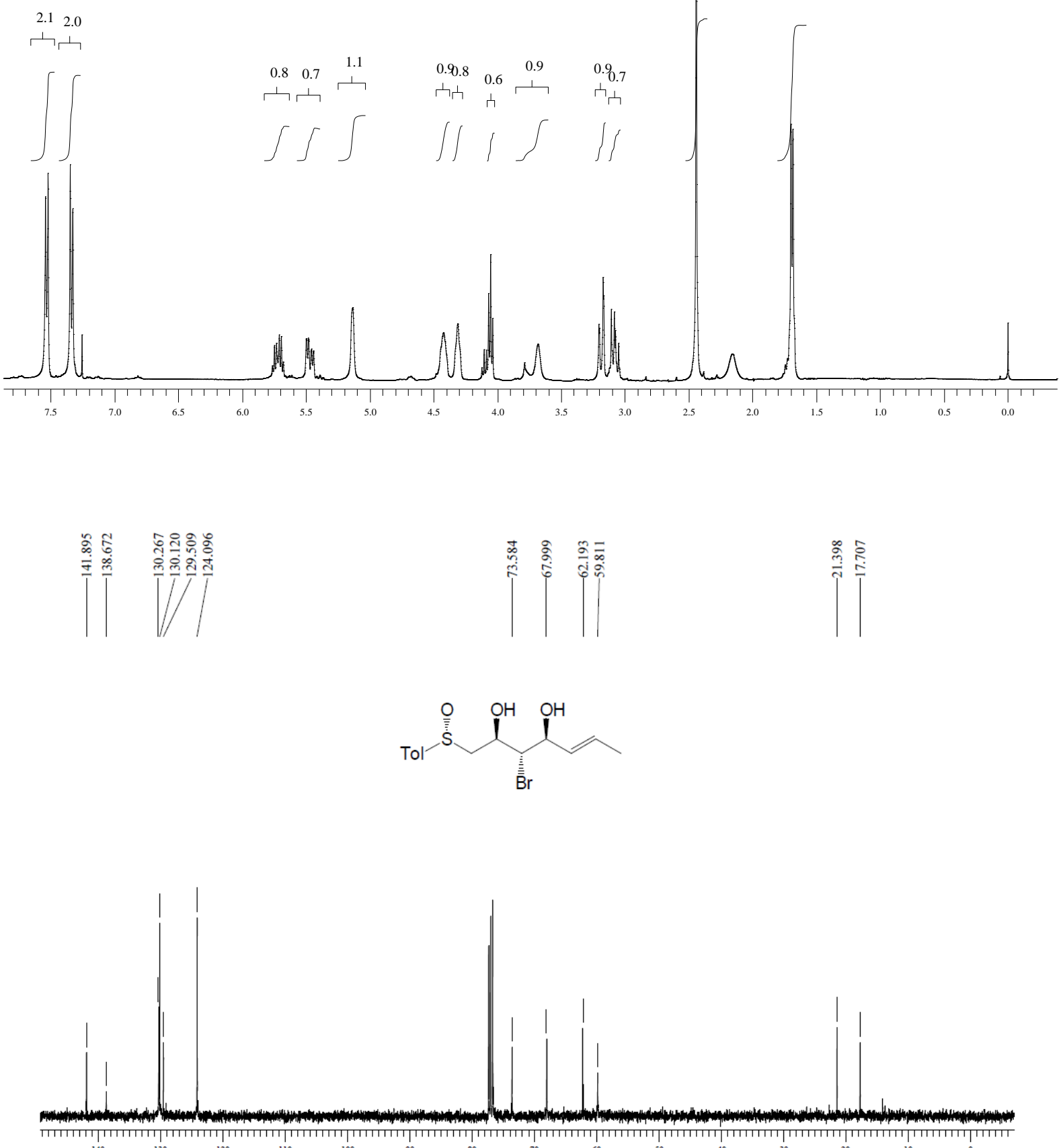
Compound 12

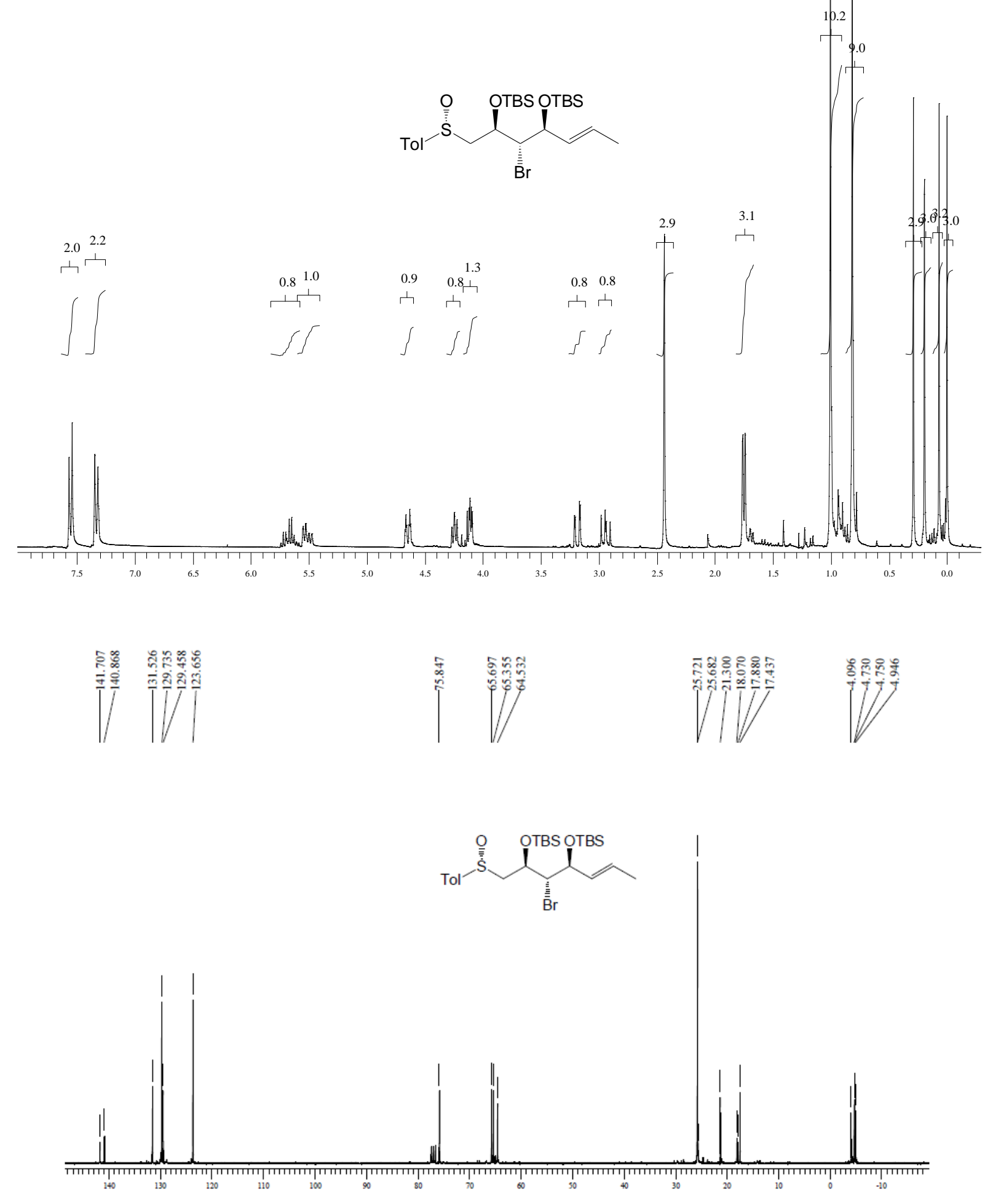


Compound 7
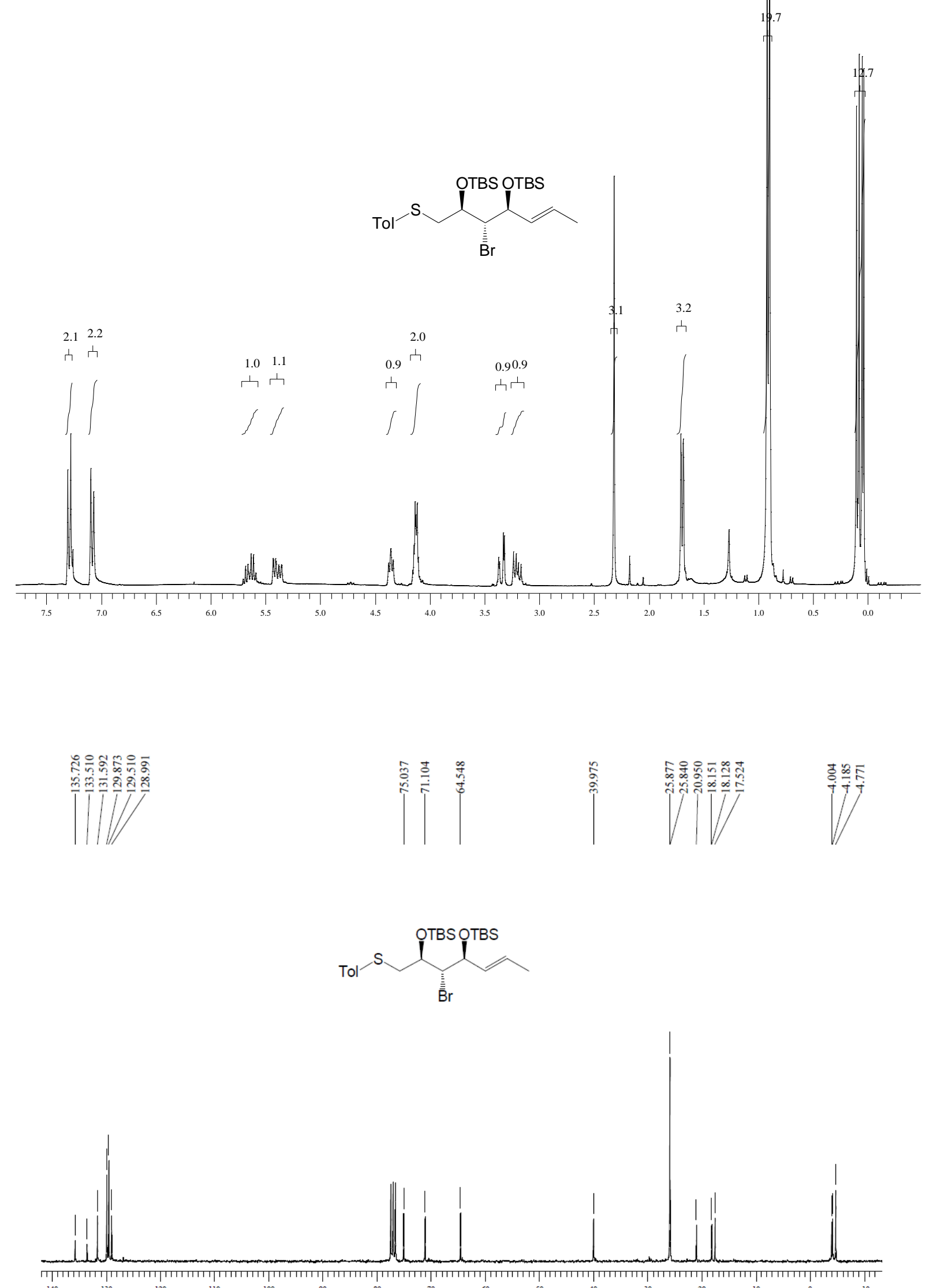
Compound 6
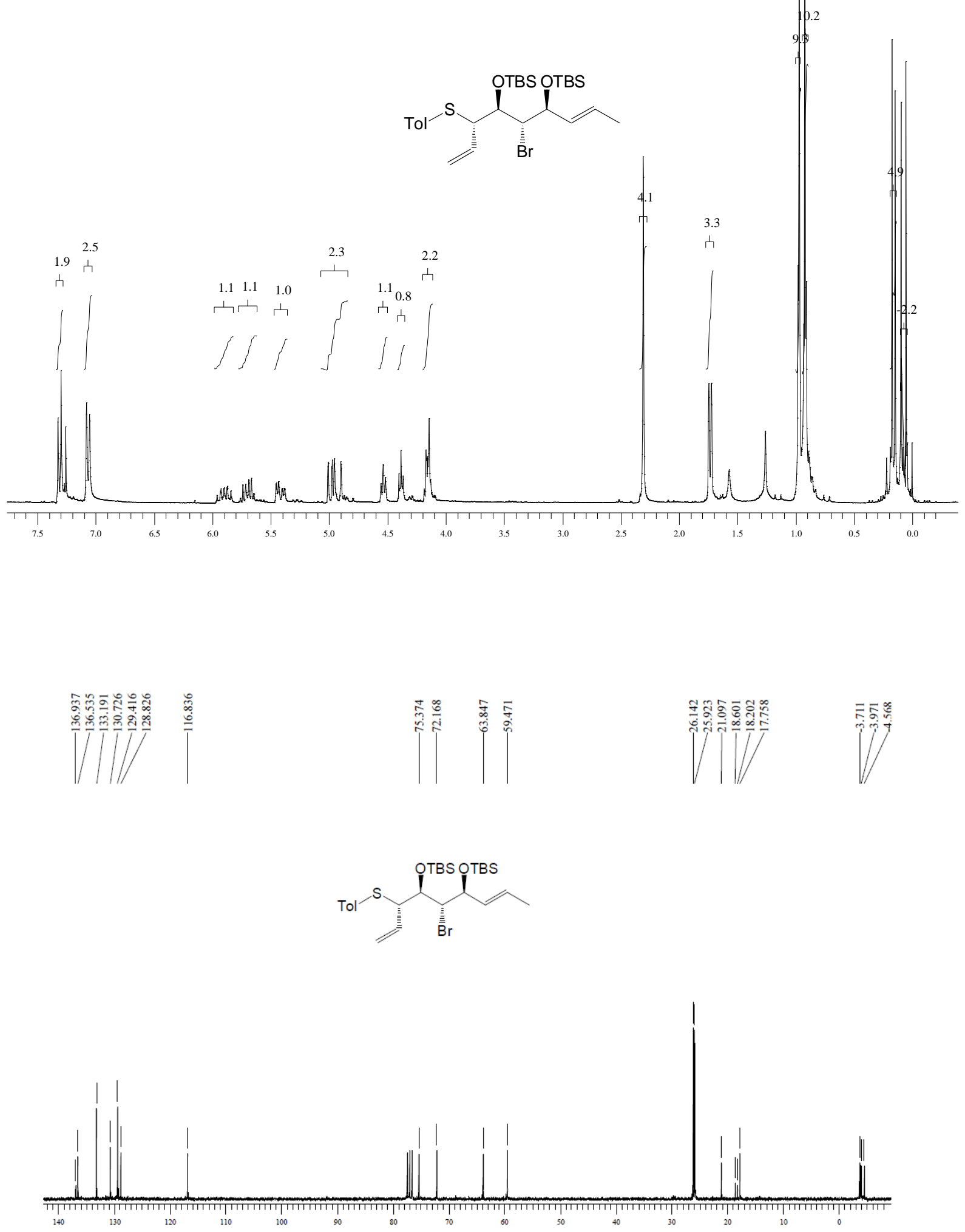
Compound 14
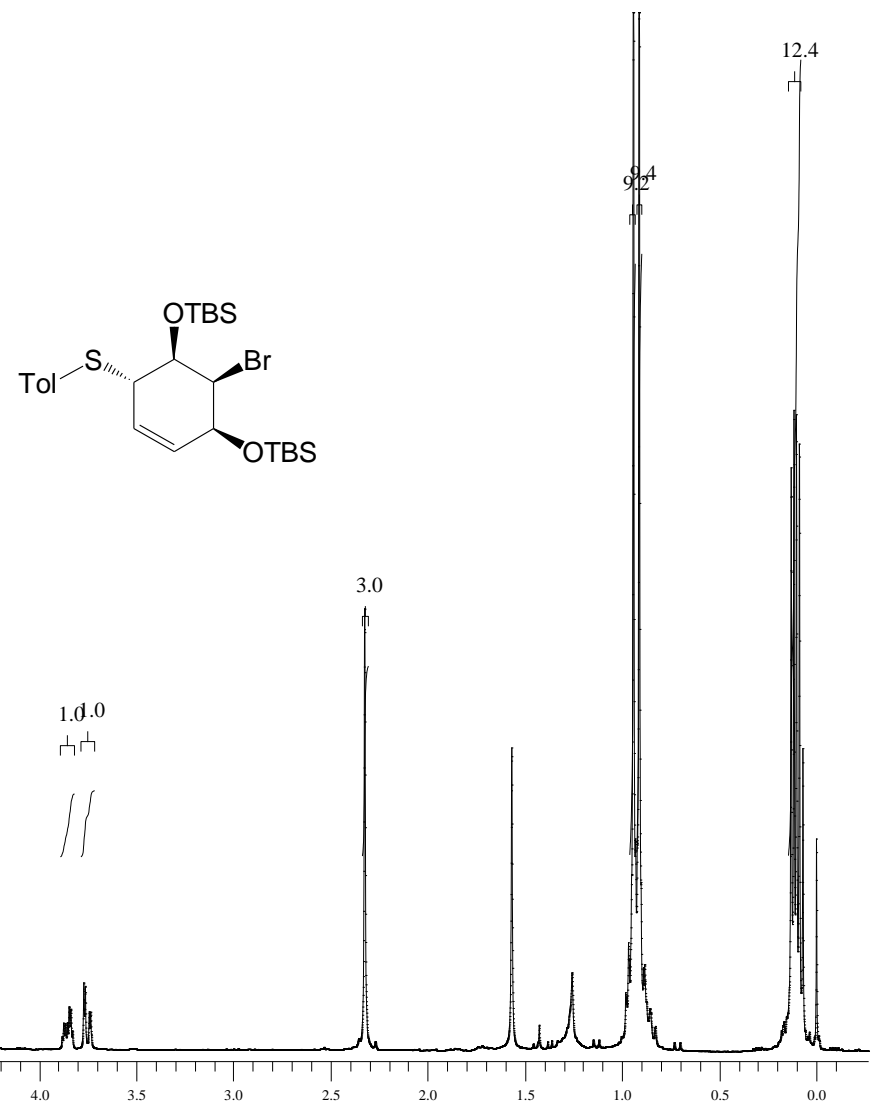

$2.0 \quad 2.1$

2.

ウ

1.0 .0

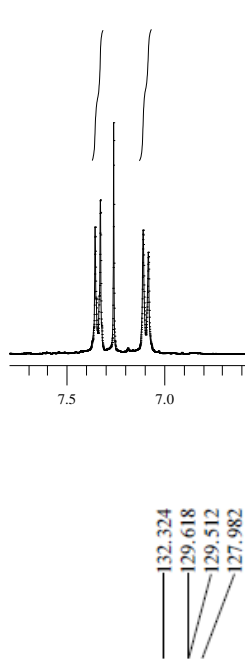

$1.0 \quad 1.0$

ウウ

$\frac{\infty}{1 /}$
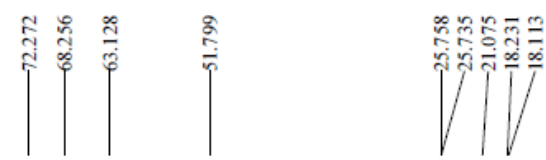

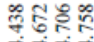
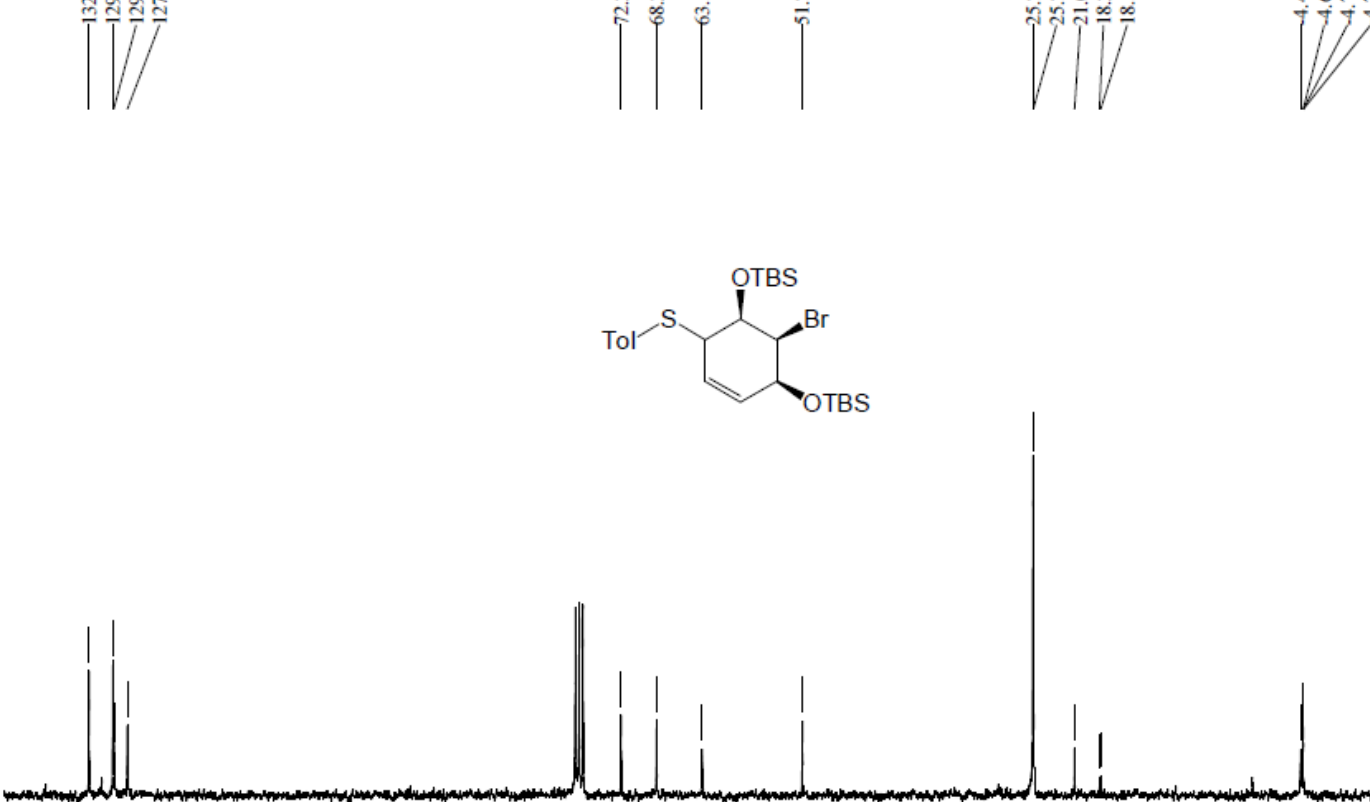

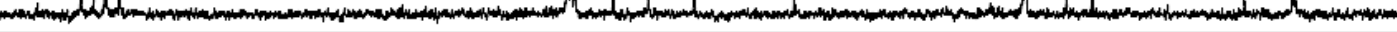

$T_{100} 130 \quad 120$

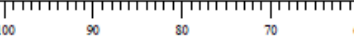


Compound 15

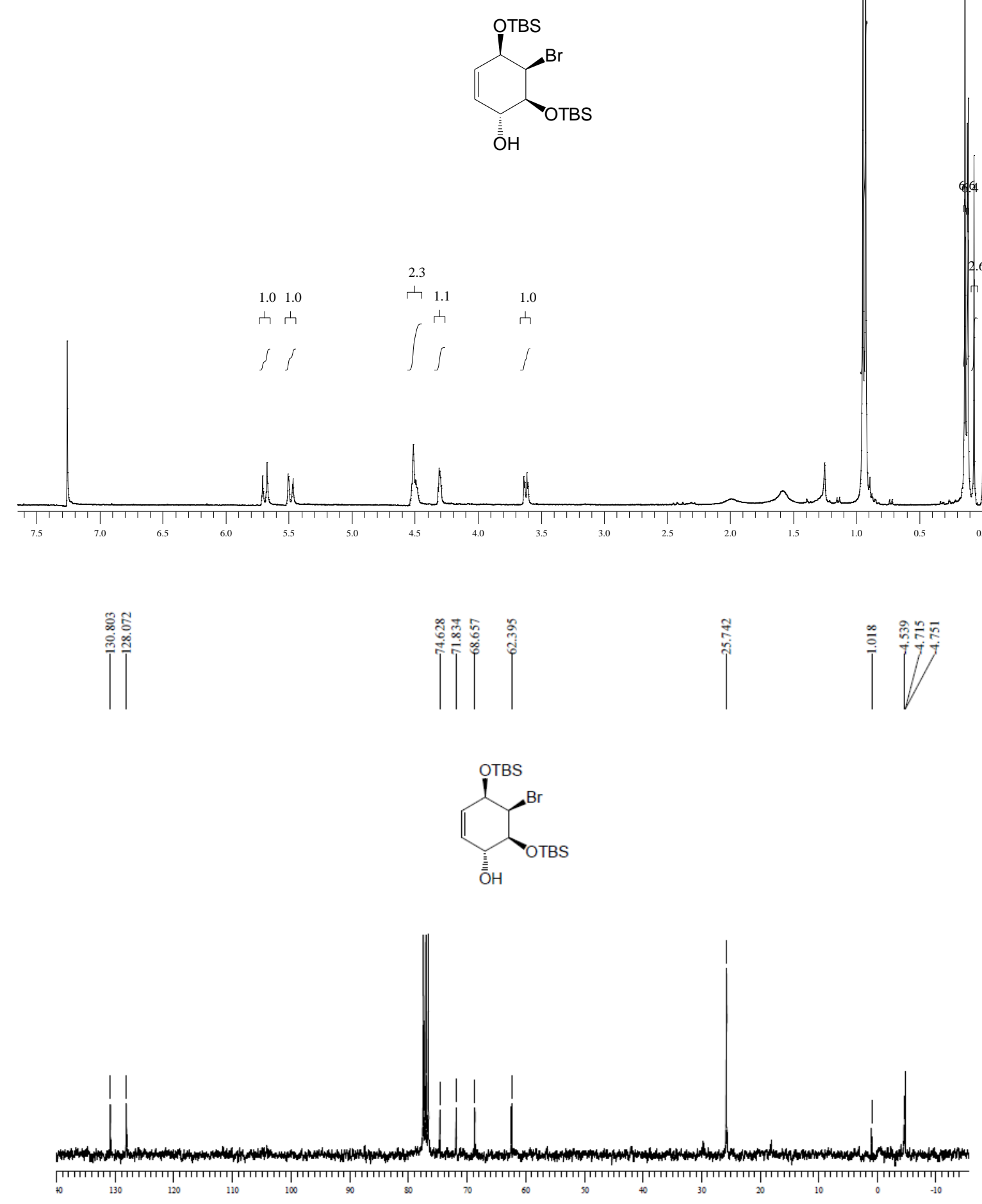


Compound 16

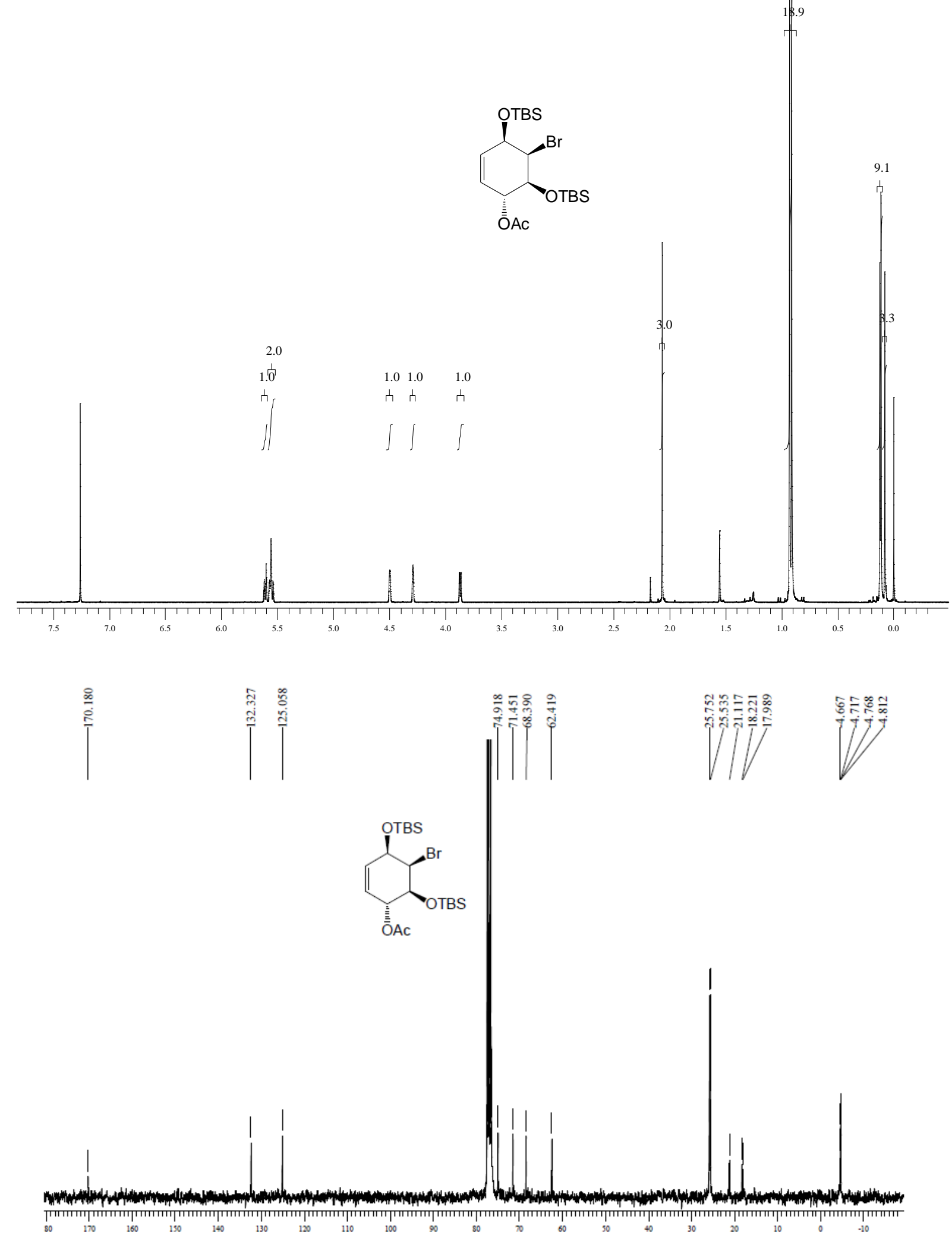




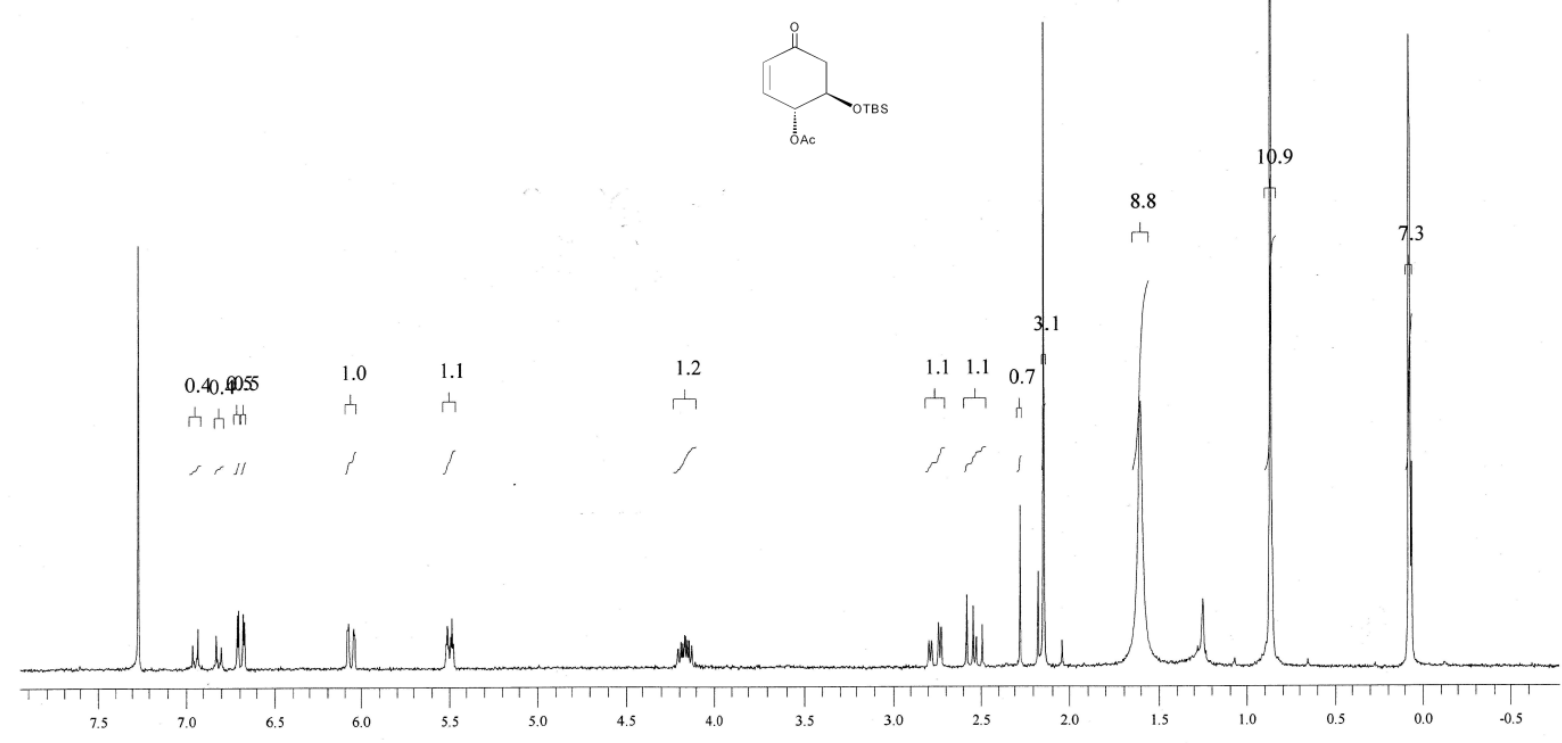

Compound 18

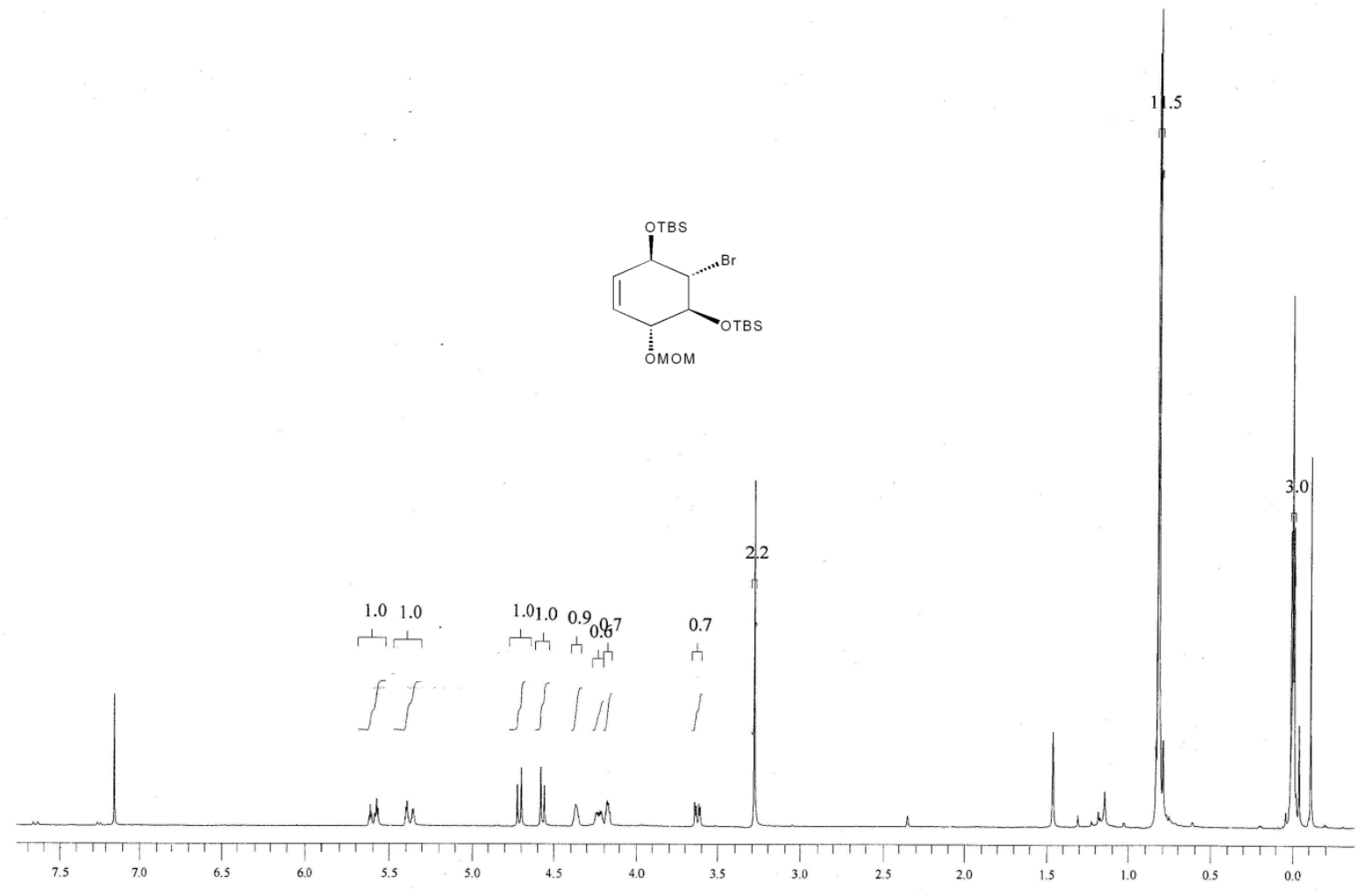


Compound 19

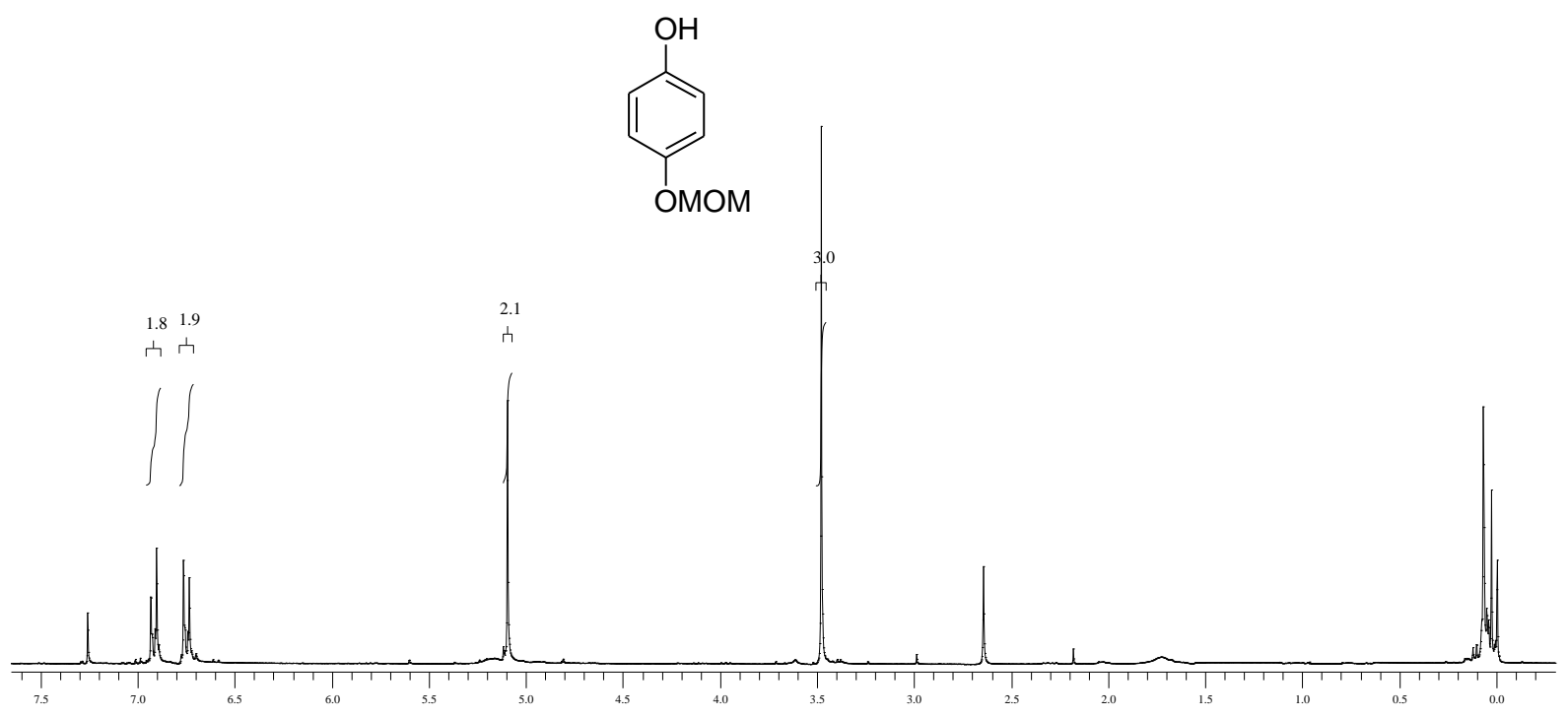


Compound 21

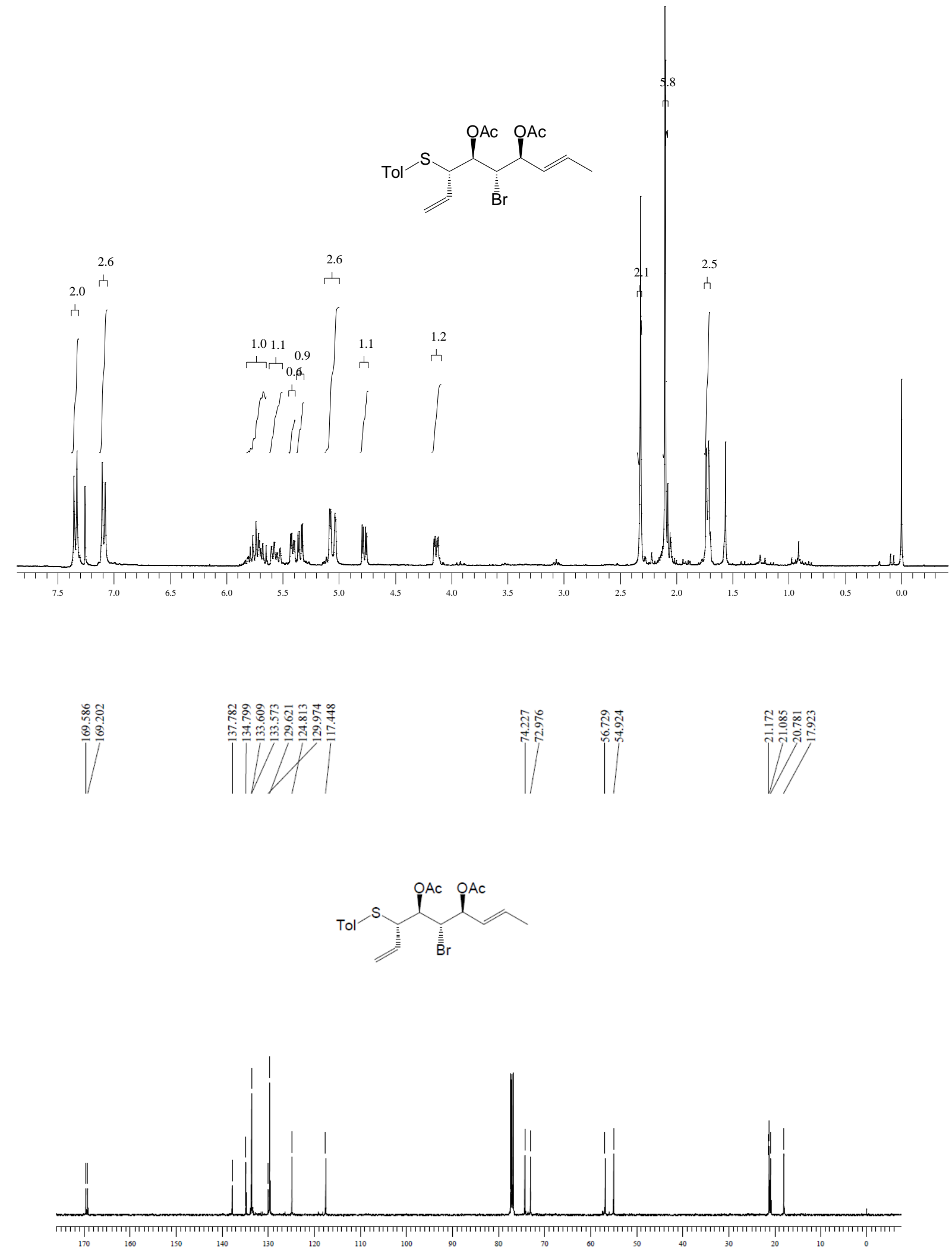



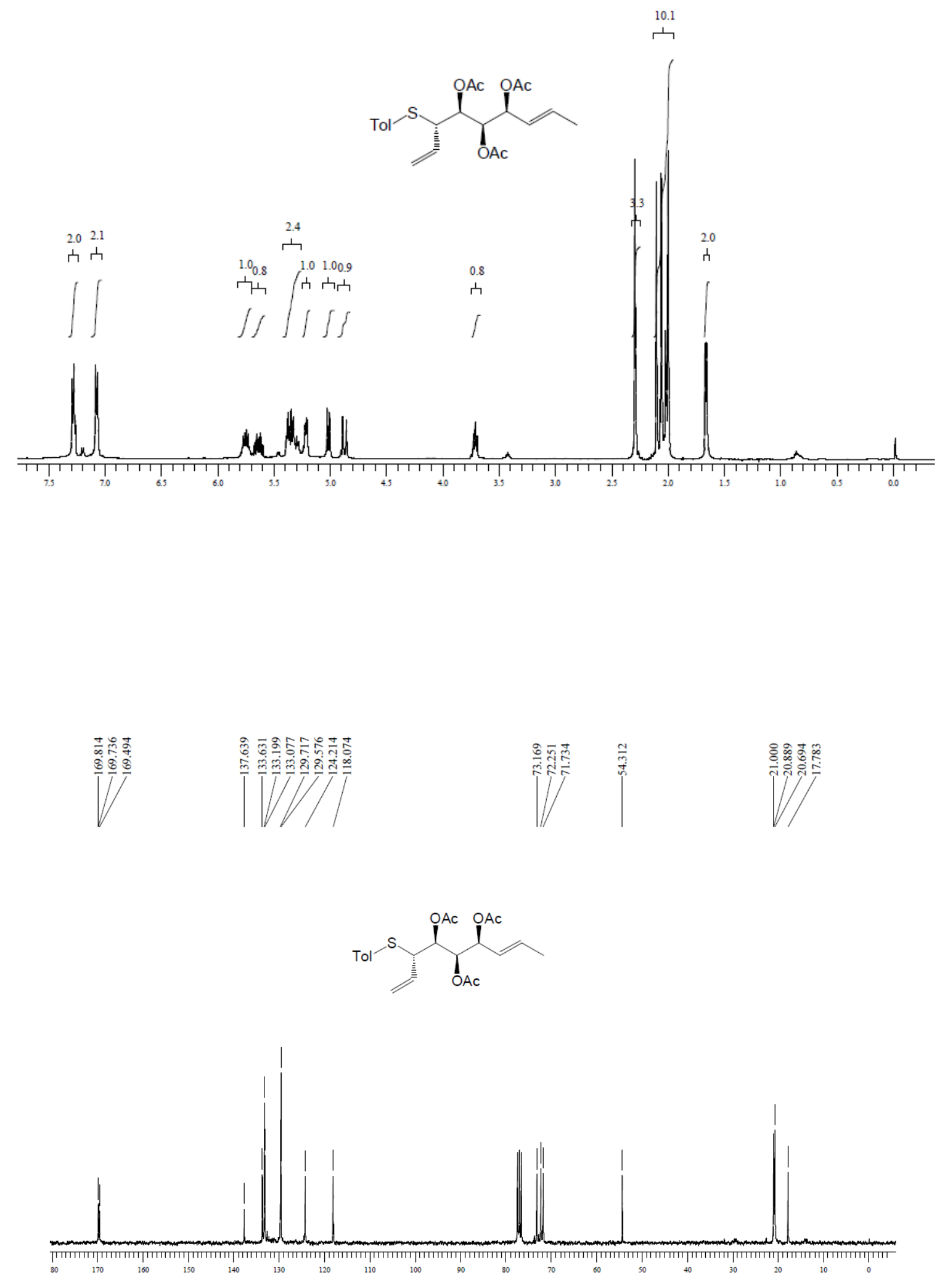


\section{Compound 23}
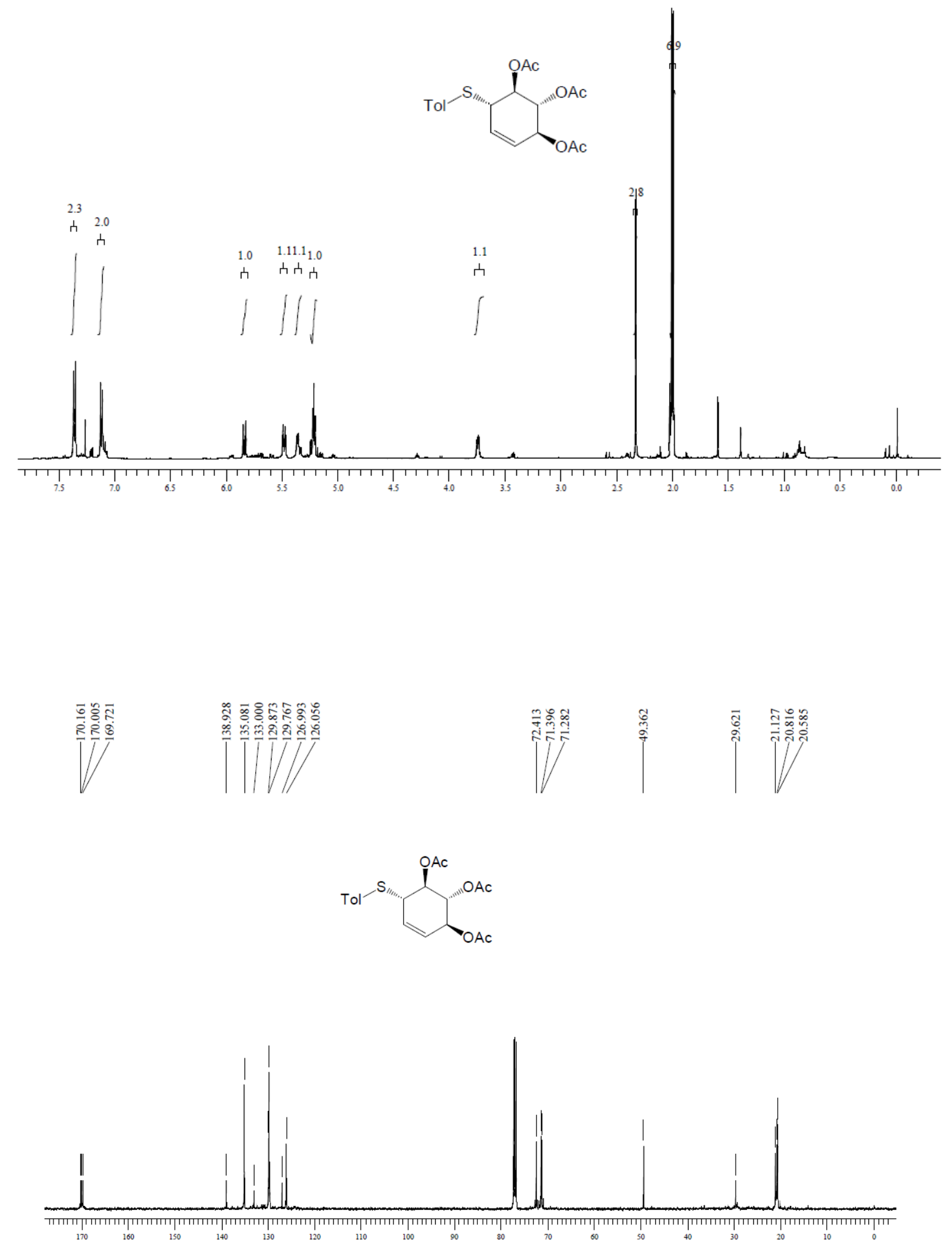


\section{Compound 24}
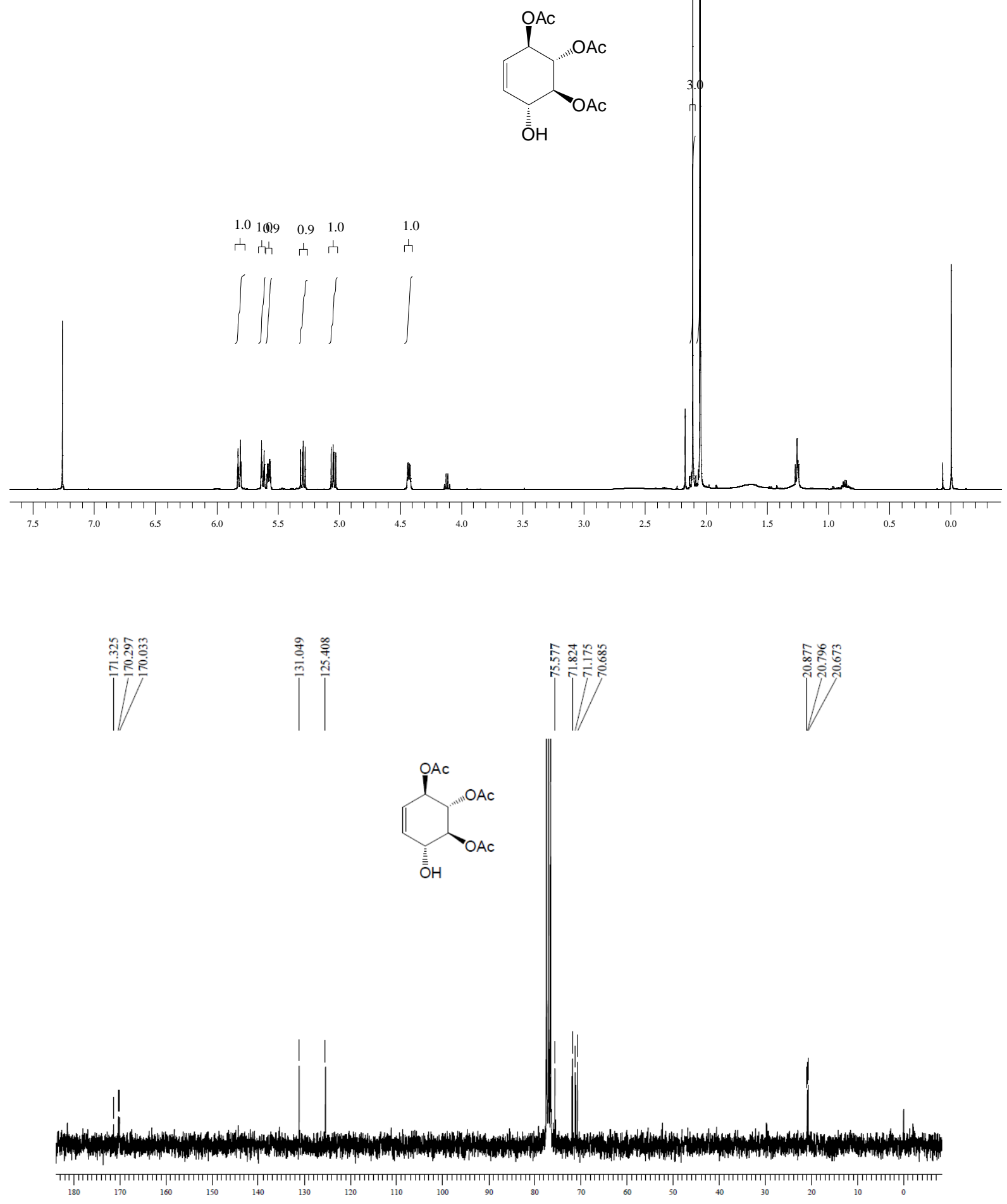


\section{Compound 25}
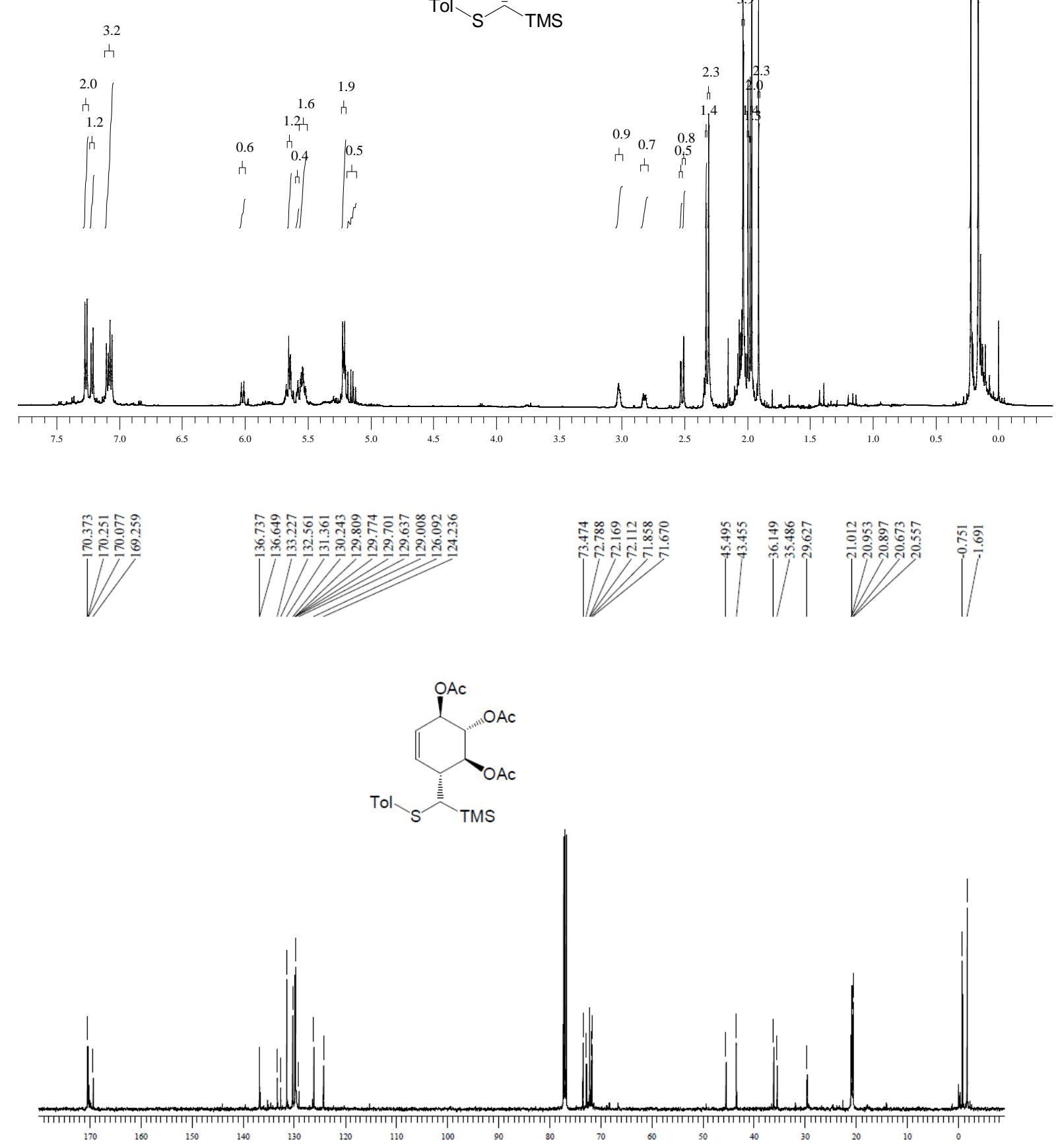
Compound 28
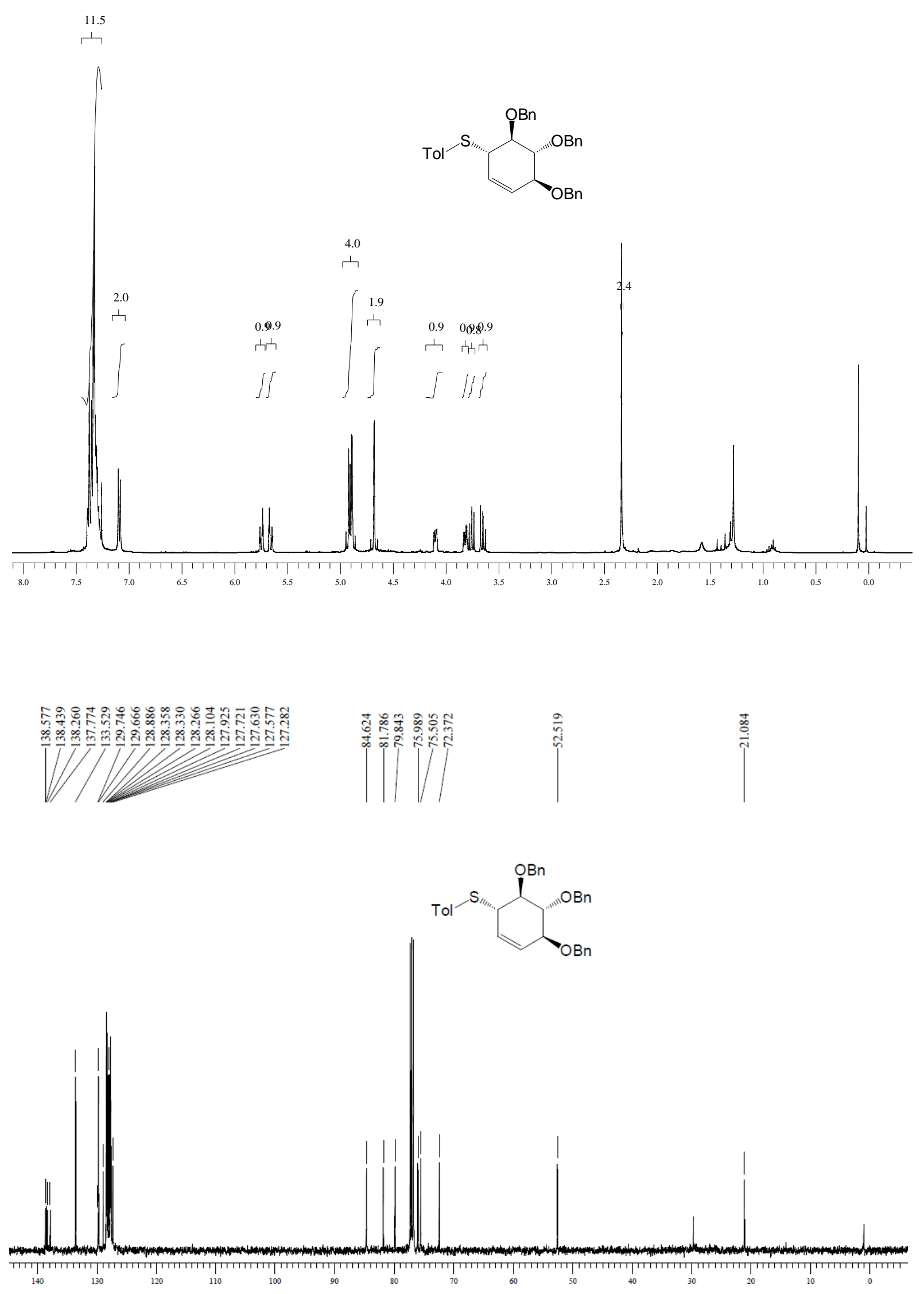

S17 
Compound 29
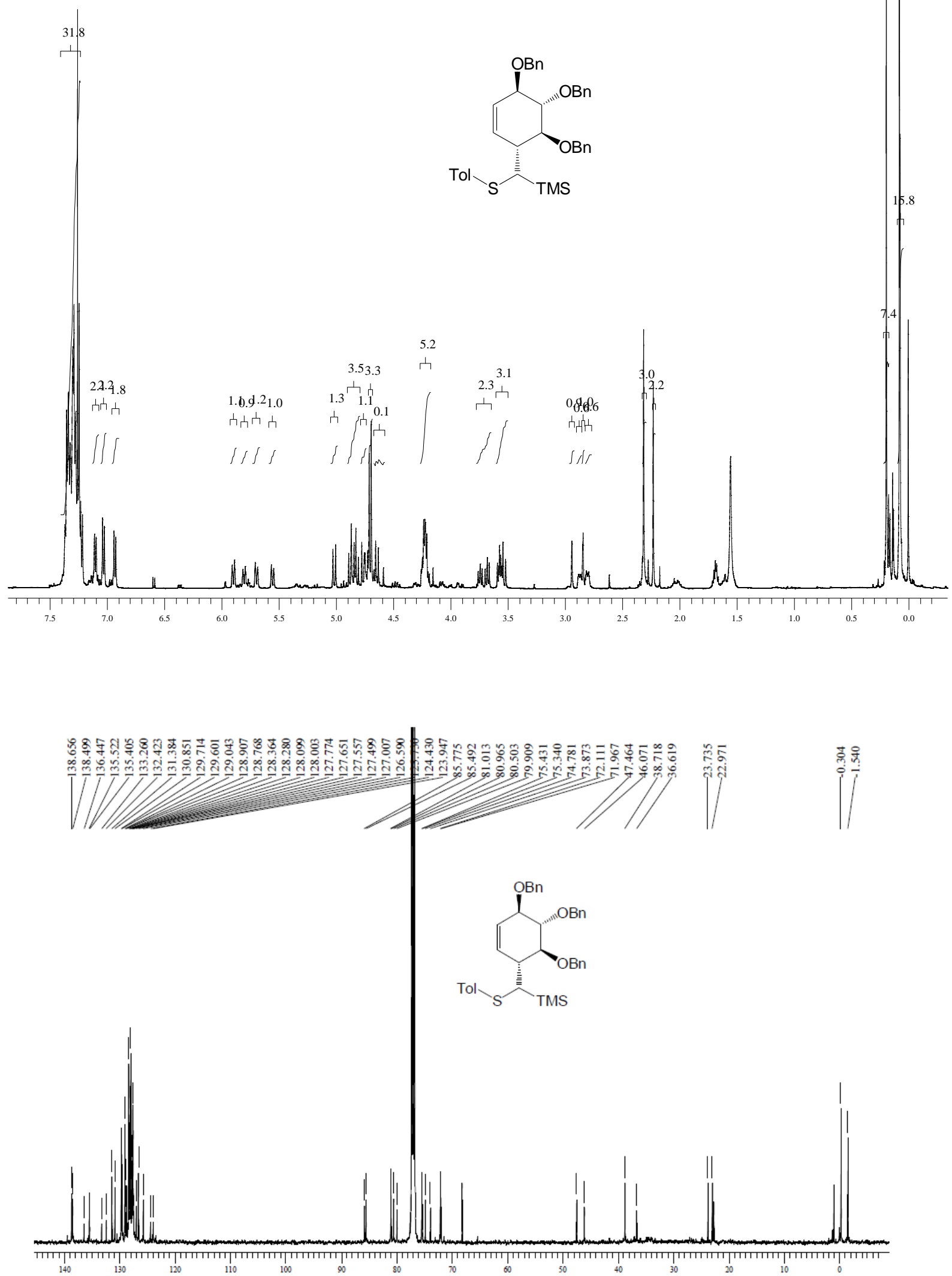
Compound 3
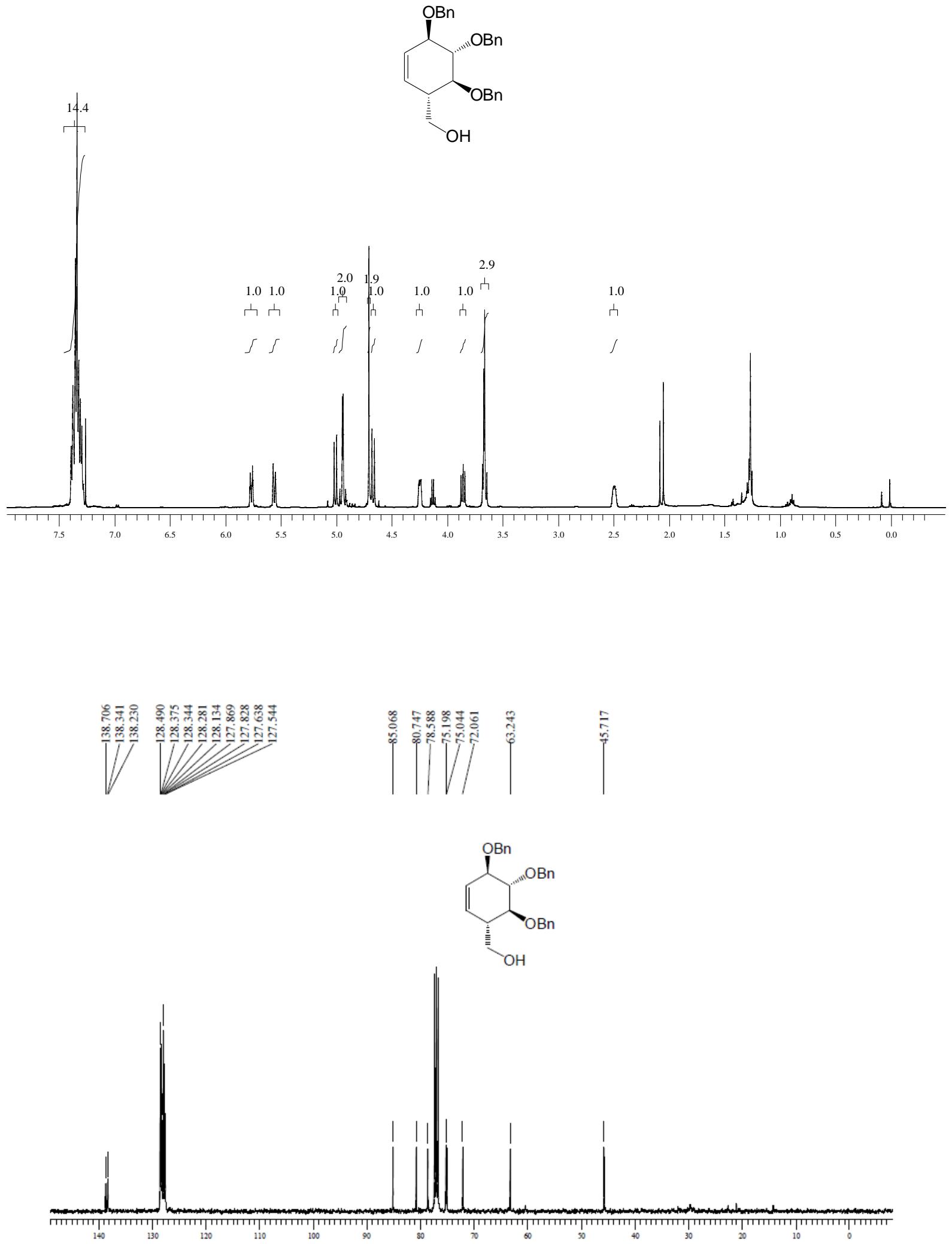
Compound 30

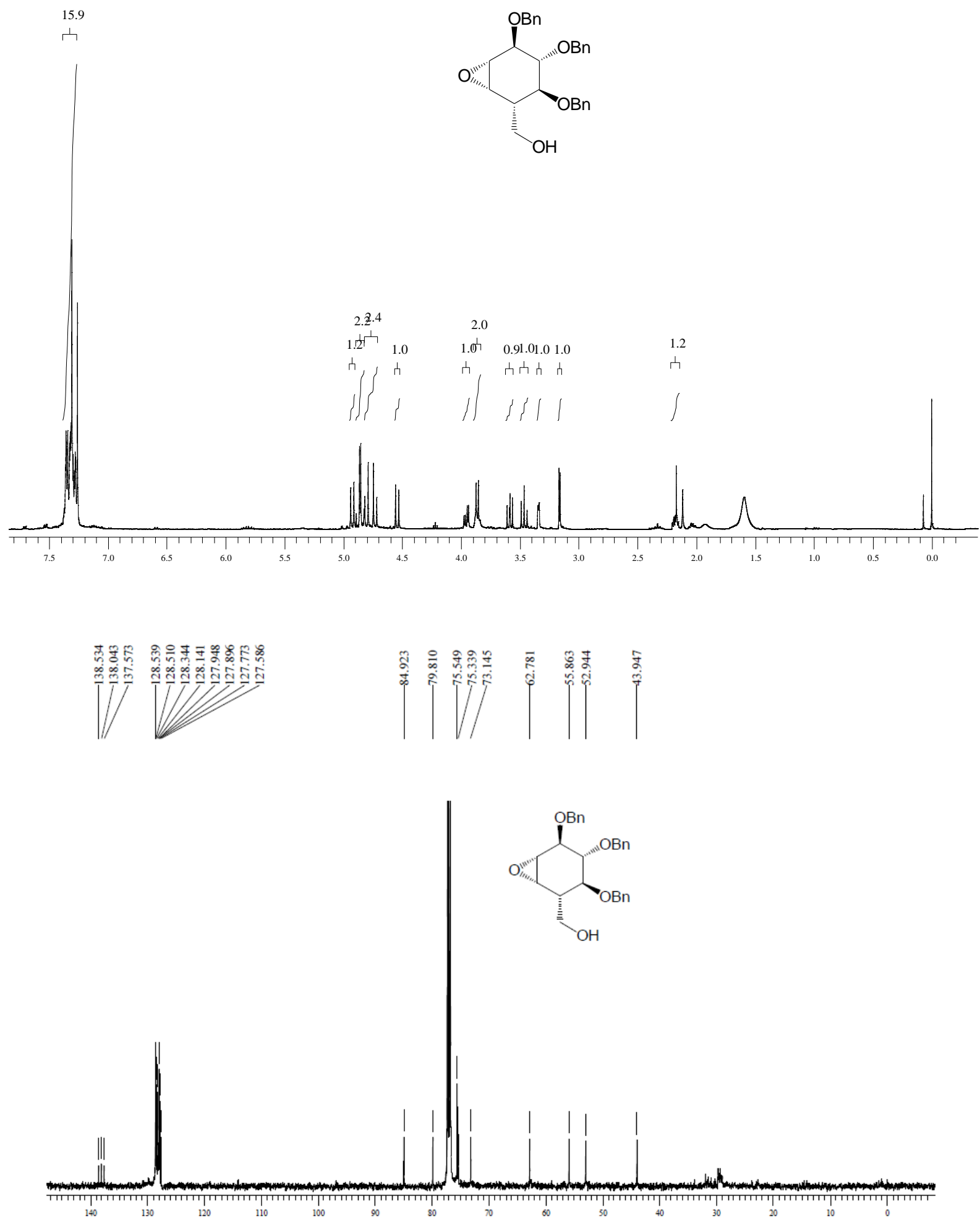




\section{Compound 31}
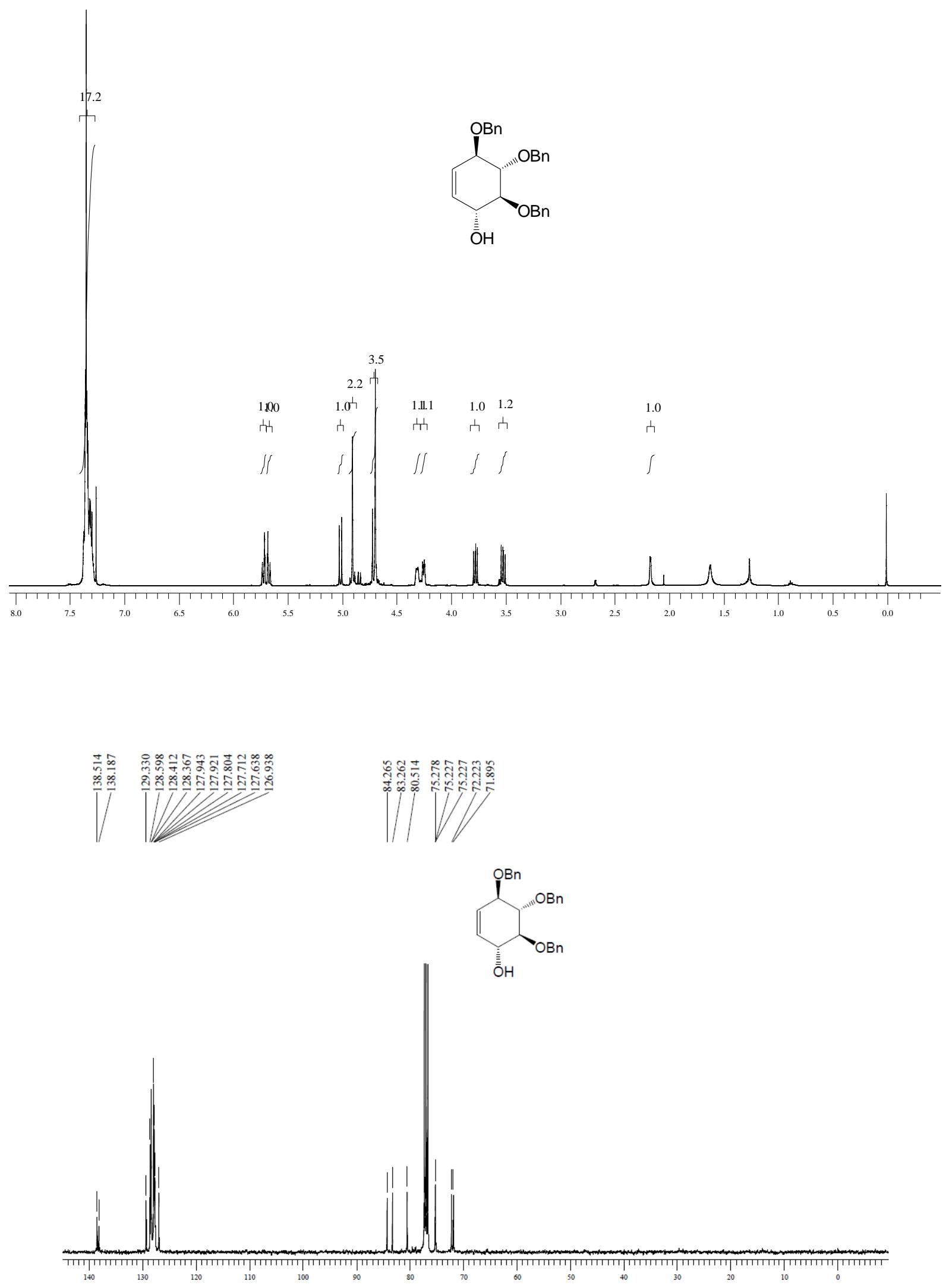


\section{Compound 32}

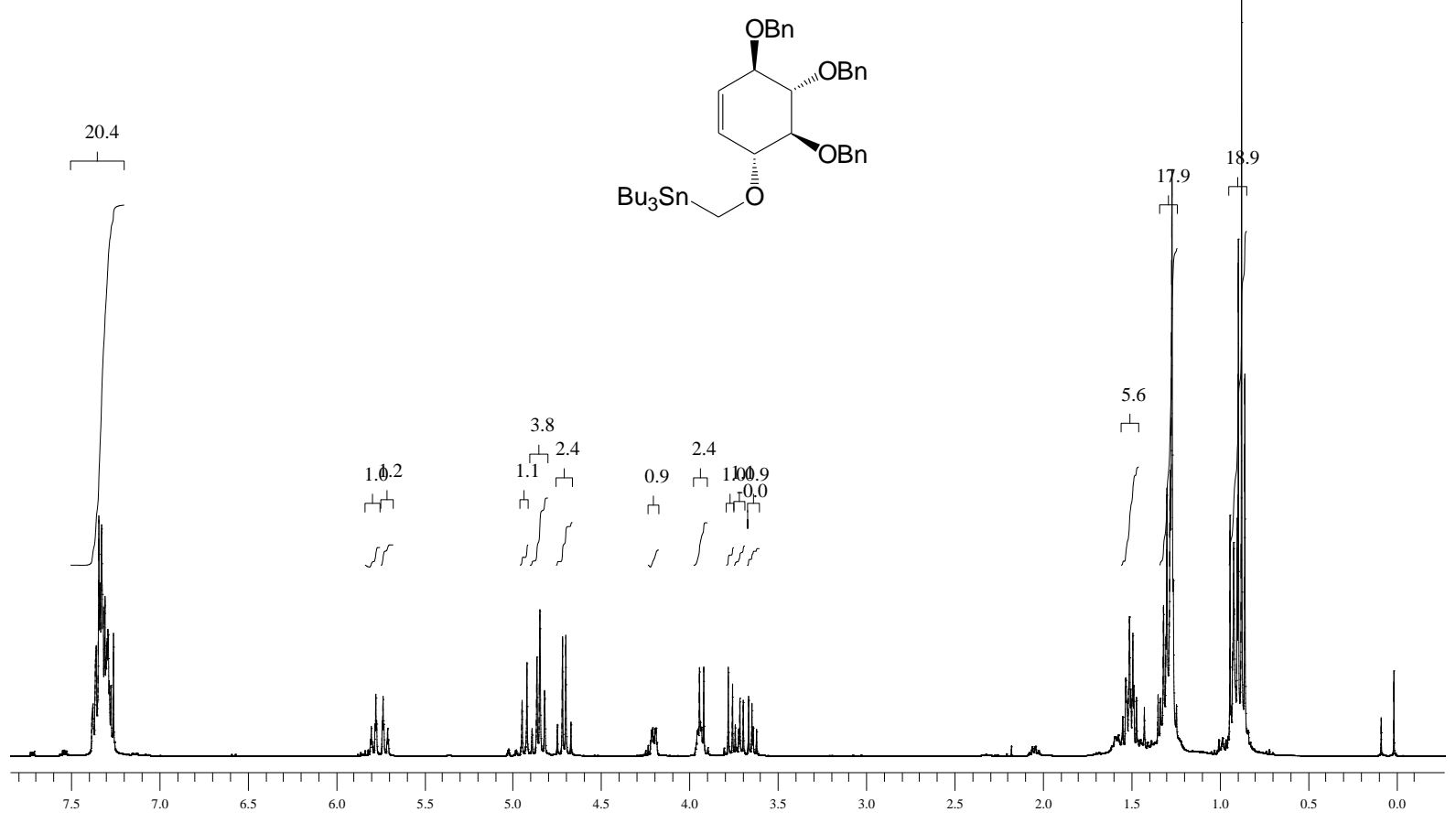

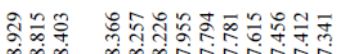

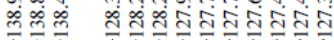

IT
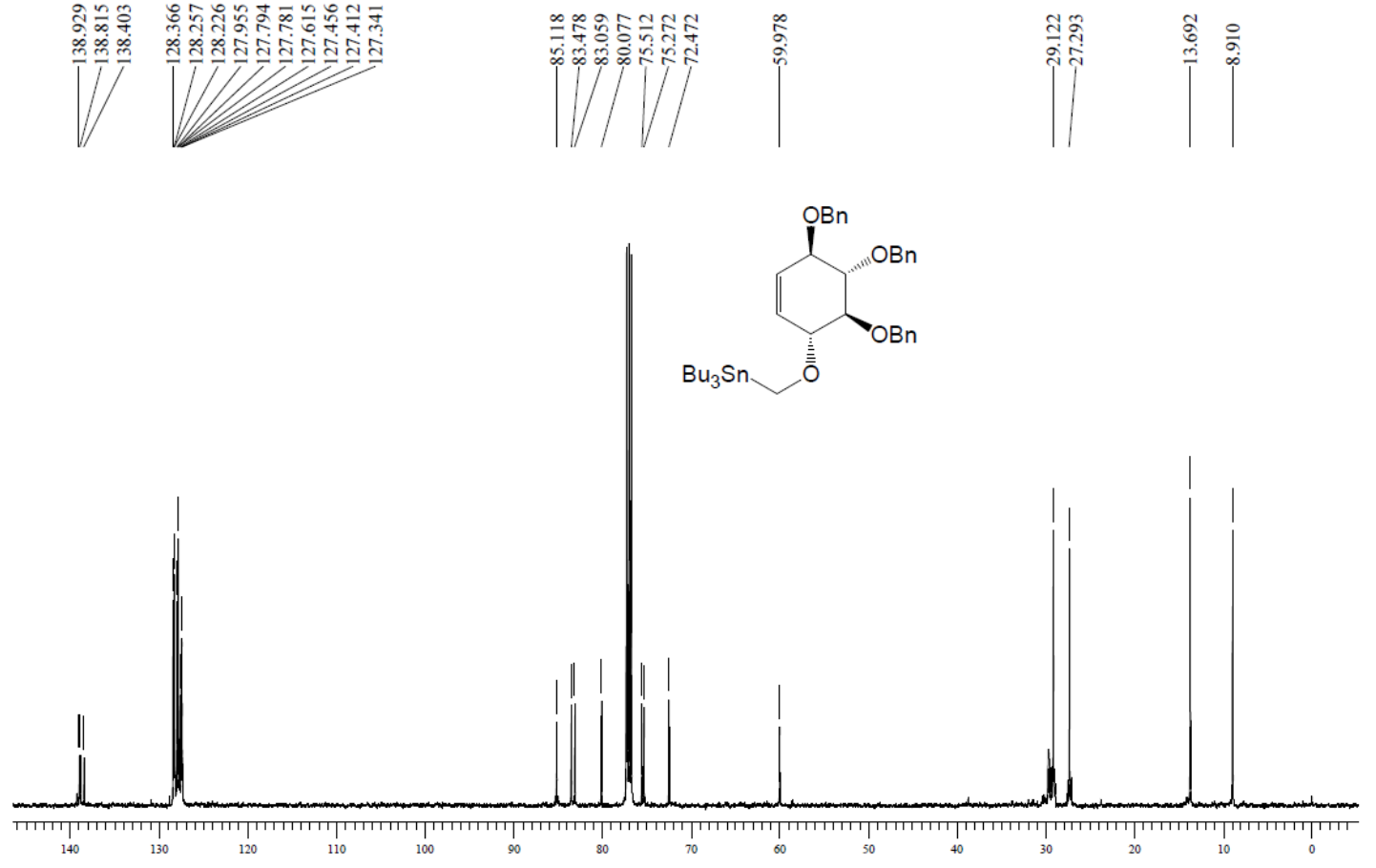


\section{Compound ent-3}

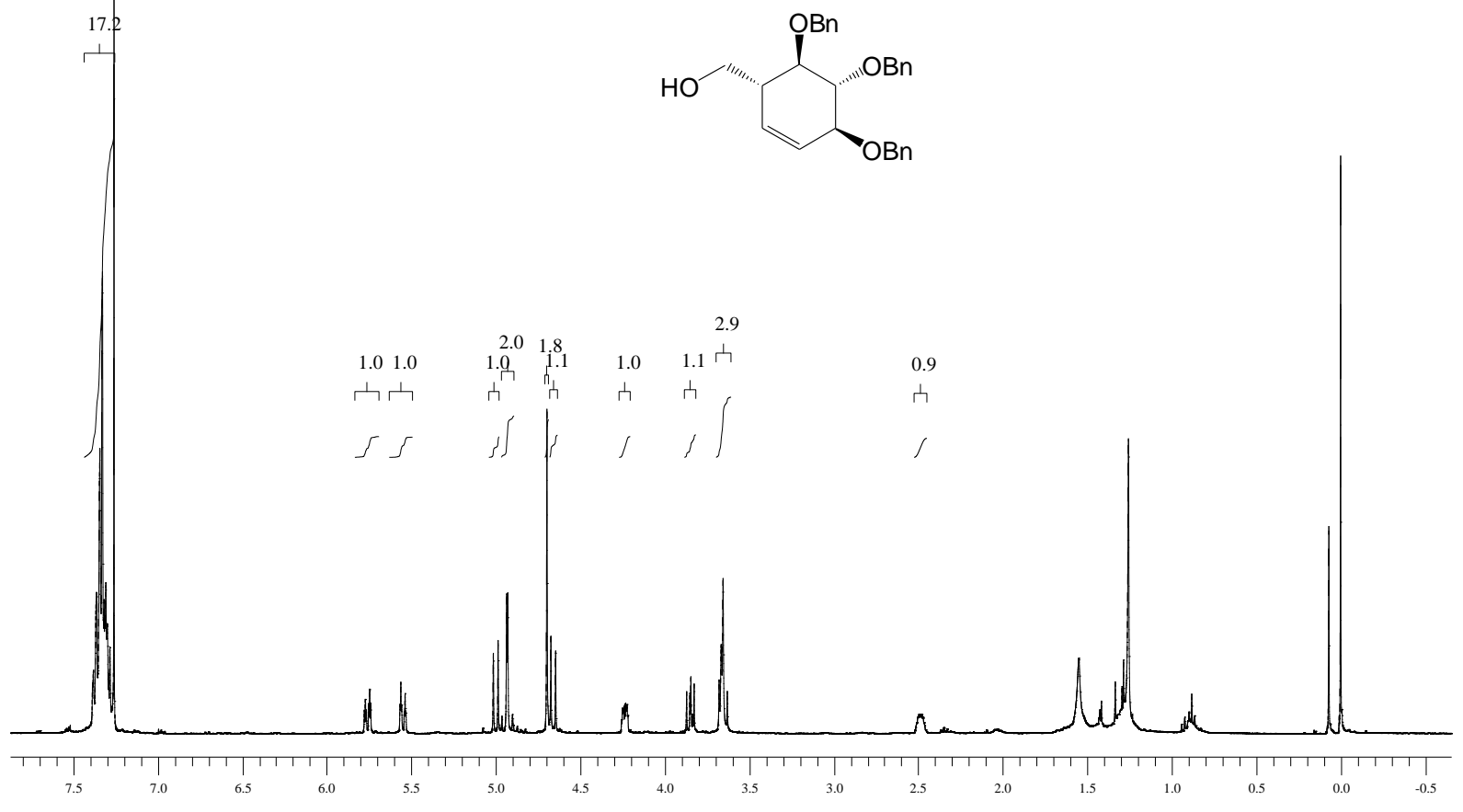

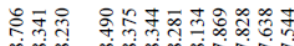

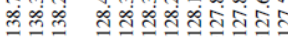

II II
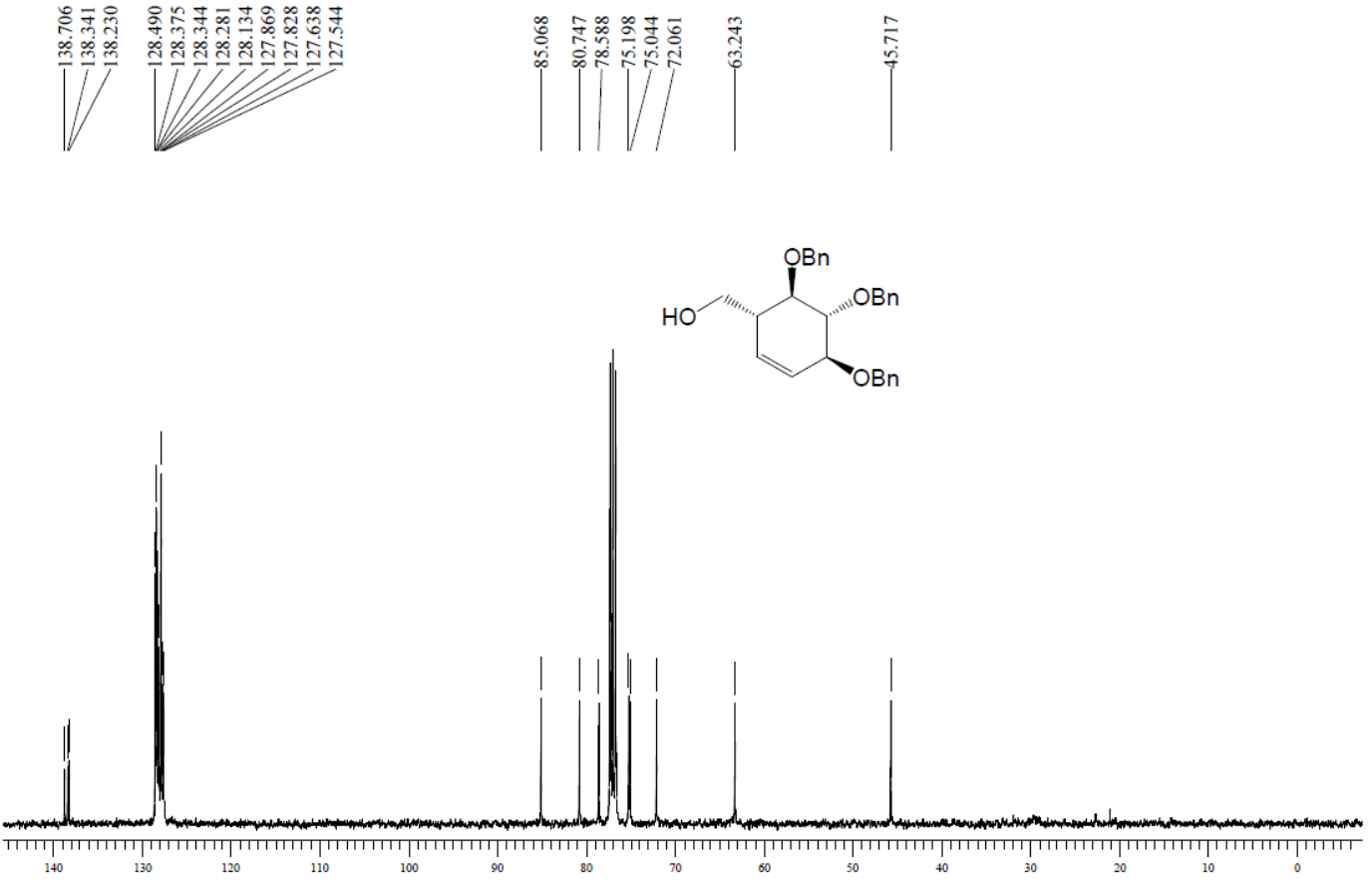


\section{Compound 34}
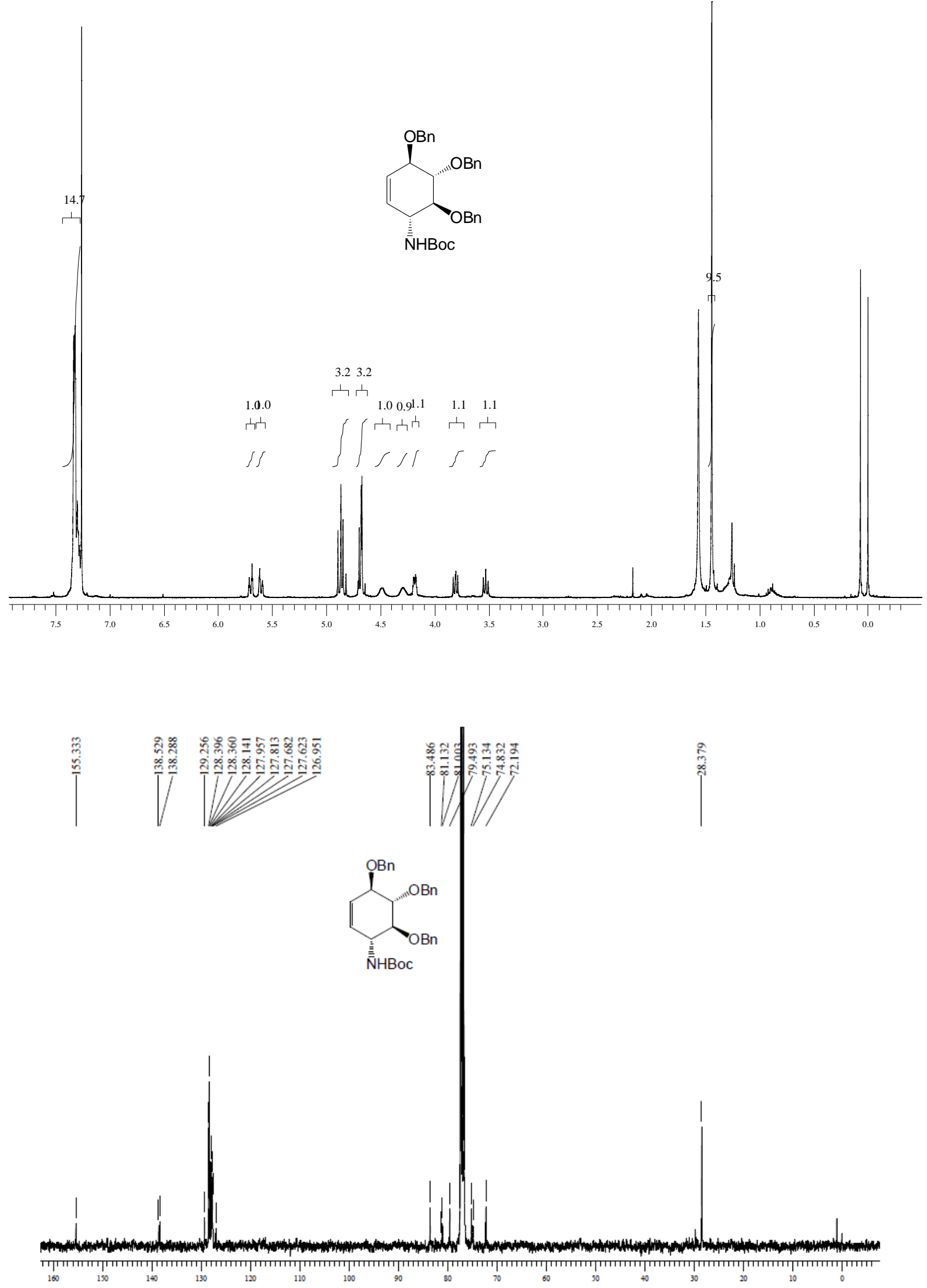